\title{
The Effects of Sulfide Inclusions on Mechanical Properties and Failures of Steel Components
}

\author{
Joseph Maciejewski
}

Submitted: 13 January 2015/Published online: 20 February 2015

(C) ASM International 2015

\begin{abstract}
A literature review was performed to assess the effects of inclusions in carbon and alloy steels on their mechanical properties. Inclusions, including brittle oxides and more ductile manganese sulfides $(\mathrm{MnS})$, affect fatigue endurance limit, fatigue crack propagation rate, fracture toughness, notch toughness, transverse tensile properties, and anisotropy of these properties with respect to the rolling direction. Significant property anisotropy has been documented, which needs to be taken into account in the design phases. Typical fracture morphologies and metallographic appearances of MnS-containing materials that the failure analyst will encounter are illustrated.
\end{abstract}

Keywords Resulfurized · Free machining - Inclusions · Manganese sulfide $\cdot \mathrm{MnS} \cdot$ Mechanical properties . Aniosotropy

\section{Introduction}

The failure analyst dealing with general industry will inevitably encounter a fractured, resulfurized steel. They can be of particular interest, since they exhibit some unusual and impressive fracture surfaces when the fracture plane is parallel to the rolling direction of the product. Ductile fractures of this kind, viewed optically are characteristically "woody" in appearance (Fig. 1). When viewed under a scanning electron microscope (SEM), the fractures exhibit separation of the manganese sulfide (MnS) inclusions from the matrix in varied and interesting morphologies (Figs. 2, 3). The

J. Maciejewski $(\square)$

Materials Testing, Applied Technical Services, Inc., 1049 Triad

Court, Marietta, GA 30062, USA

e-mail:jmac@atslab.com question for the analyst becomes whether the inclusion content of the steel was in any way causal to the failure, or was it only an eye-catching feature that reflects the natural fracture character of the material.

Indeed, the author has been asked specifically what deficiencies (if any) resulfurized steels may pose with respect to mechanical properties and design considerations. In particular, what failure potential may be present in these steels in the quenched and tempered condition.

Manganese is added to all steels in order to prevent the formation of iron sulfide. This low melting point phase results in hot forming difficulties and ruptures [1]. The addition of sufficient manganese preferentially converts the sulfur to higher melting point manganese sulfides, which are elongated during hot working because of their high plasticity at these temperatures. Inclusion shape control by specific elemental additions can reduce the aspect ratio of the manganese sulfides by modifying its hot plasticity [2-5]. The significance of this point will become clear later, as the effects of elongated inclusions are discussed. Standard carbon steel grades are limited to $0.050 \mathrm{wt} . \%$ maximum sulfur. Alloy steels are generally limited to 0.040 wt. \% sulfur [6].

The addition of significantly higher concentrations of sulfur (hence the term resulfurized), while simultaneously ensuring a greater than stoichiometric amount of manganese, obviously results in a higher content of inclusions. The practical application is a significant improvement in the machining rate of the alloy as compared with a normal grade of the same carbon content [7]. This is the origin of the term "free machining" for the same grades of material. For instance, there is a $45 \%$ increase in the machining rate (quantity of parts) for a given tool life when changing from AISI 1045 steel to AISI 1144 resulfurized grade [7]. Increased "machinability" can be measured in many other 


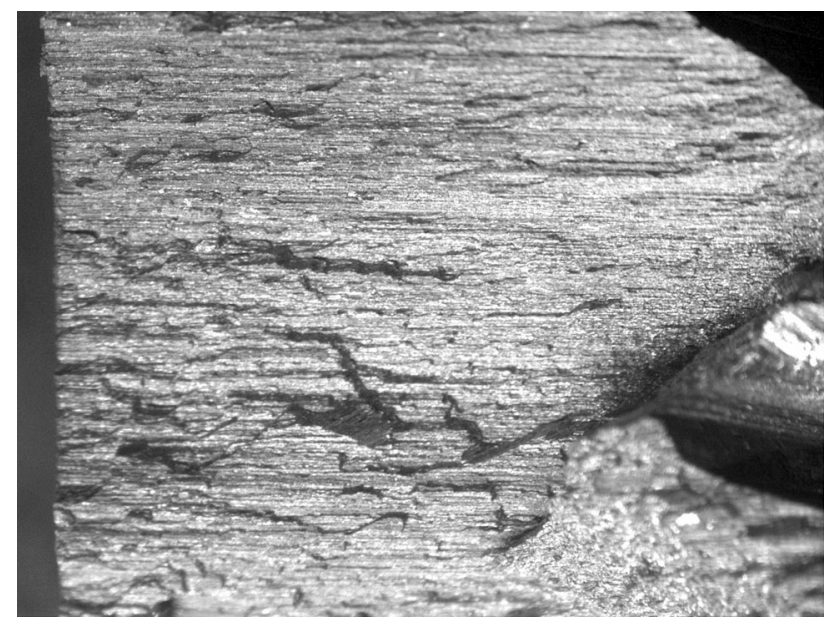

Fig. 1 Optical image of a typical woody fracture appearance of a resulfurized material in ductile overload on a plane parallel to the longitudinal direction

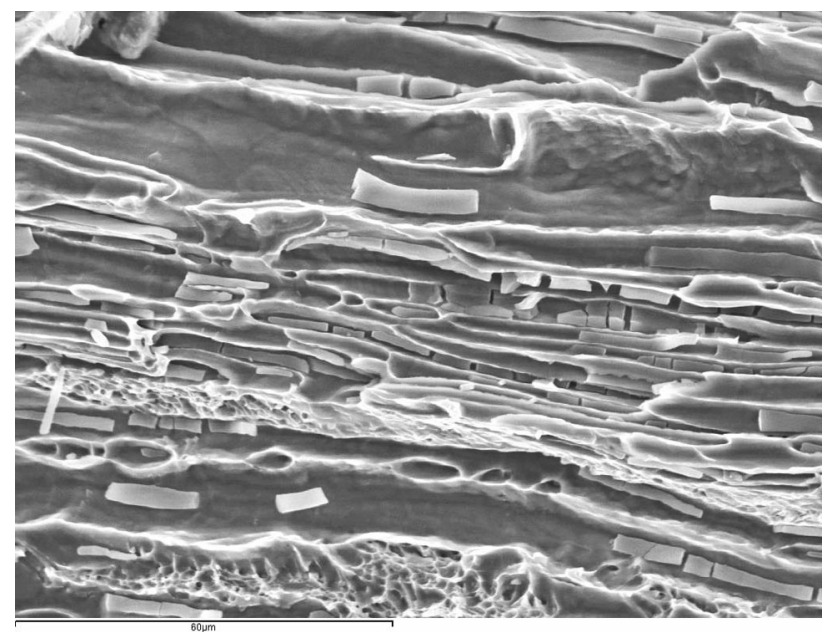

Fig. 2 SEM image of one of the most common fracture appearances of resulfurized material. Ductile overload on a plane parallel to the rolling direction, resulting in a woody appearance at lower magnification

ways, such as lower cost due to removal of secondary operations as a result of improved surface finish on resulfurized parts. The mechanism of improved machinability is through a chip-breaking action as tools cut through the material, rather than tolerating long, stringy chip segments. The MnS inclusions act as discontinuities to allow the chips to break, act as self-lubricating agents, and as antistick agents on the tool. These properties all lead to less power applied to the machine tool and less heat generation [7].

The AISI $11 \mathrm{xx}$ grades are the common U.S. designations for resulfurized carbon steels, and grade AISI 1144 ( $\sim 0.44$ wt.\% carbon) is one of the most common alloys of this type that the analyst will encounter. AISI 1045 plain

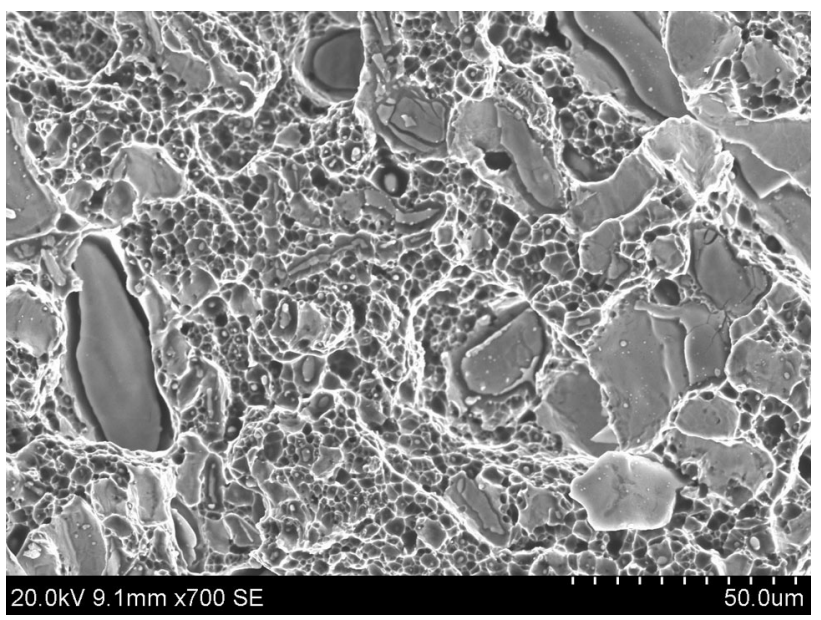

Fig. 3 Manganese sulfide inclusions on a plane of ductile overload perpendicular to the rolling direction. The inclusions are not symmetric since the original rolled blank was used in a later forging operation

carbon steel ( $\sim 0.45$ wt.\% carbon) can be heat treated to the same strength ranges but contains a lower sulfide inclusion content. Resulfurized grades of steel are generally specified with $0.08-0.13$ wt.\% sulfur, but AISI 1139 and 1144 are allowed $0.13-0.20$ and $0.24-0.33$ wt.\% sulfur, respectively.

The elongated manganese sulfide inclusions, or "stringers", are visible in metallographic section, as-polished, particularly when viewing the longitudinal plane. The orientation of these inclusions relative to the shape of the part and to the direction of stress, as well as their particle density, are important variables affecting properties and potential for failure. An example of $\mathrm{MnS}$ inclusions on a longitudinal plane near a corner feature of a component is shown in Fig. 4. One can already anticipate that easy crack formation might occur if the corner feature was loaded in bending or transverse tension. Since $\mathrm{MnS}$ inclusions are not affected by heat treatment, they can be present in any steel microstructure, such as ferritic/pearlitic, martensitic, or bainitic (Fig. 5). Figure 6 shows manganese sulfide stringers on a longitudinal section plane and adjacent fracture features. The interaction of the inclusions during ductile rupture and the formation of the characteristic woody fracture appearance can be visualized.

The purpose of this review was to summarize the effects that elongated sulfide stringers, characteristic of resulfurized grades of steel, have on the mechanical properties of steels. The effects of elongated inclusions of other chemical composition may be assumed to be similar, since all will have lower interface bonding strength than the bulk material to itself. A comparison with carbon steels of the same strength level (i.e., AISI 1035-1045) was performed whenever possible. The quenched and tempered condition at a hardness level of $30-50 \mathrm{HRC}$ is a common application 


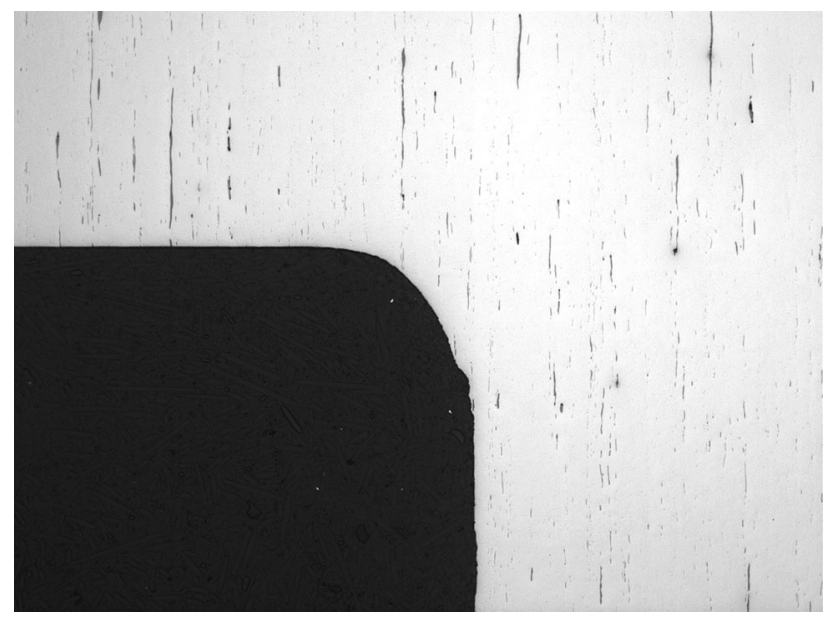

Fig. 4 Typical appearance of MnS inclusions on a longitudinal plane and their interaction with a corner feature

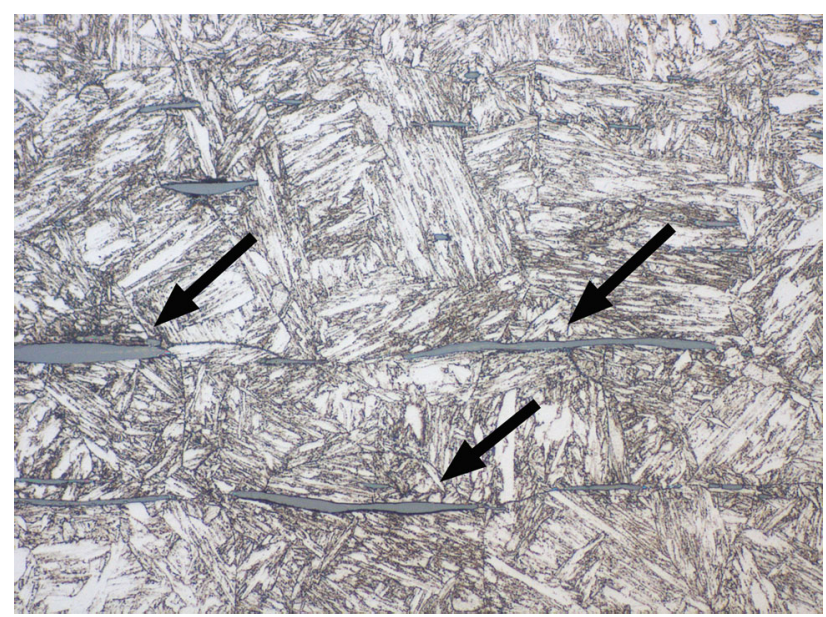

Fig. 5 Manganese sulfide inclusions (arrows) present in a hardened, bainitic microstructure

for these steels. This corresponds to approximate tensile strengths from 950 to $1760 \mathrm{MPa}$ according to ASTM A 370. The general literature available on the influence of $\mathrm{MnS}$ on the mechanical properties of steels contained little direct comparison between carbon steels and similar resulfurized grades in the quenched and tempered condition. This is doubtless due to research funding being targeted to specific alloys. For instance, alloy steels were more often analyzed. Therefore, in assessing the differences between carbon and resulfurized steels, only the general effects of sulfides and other inclusions could be evaluated.

Alloying additions to steel generally affect hardenability, corrosion resistance, and solid solution hardening. However, the effects of $\mathrm{MnS}$ in a crack-like or notch-like effect are expected to be similar in alloy steel martensite and carbon steel martensite. Therefore, alloy steel data are

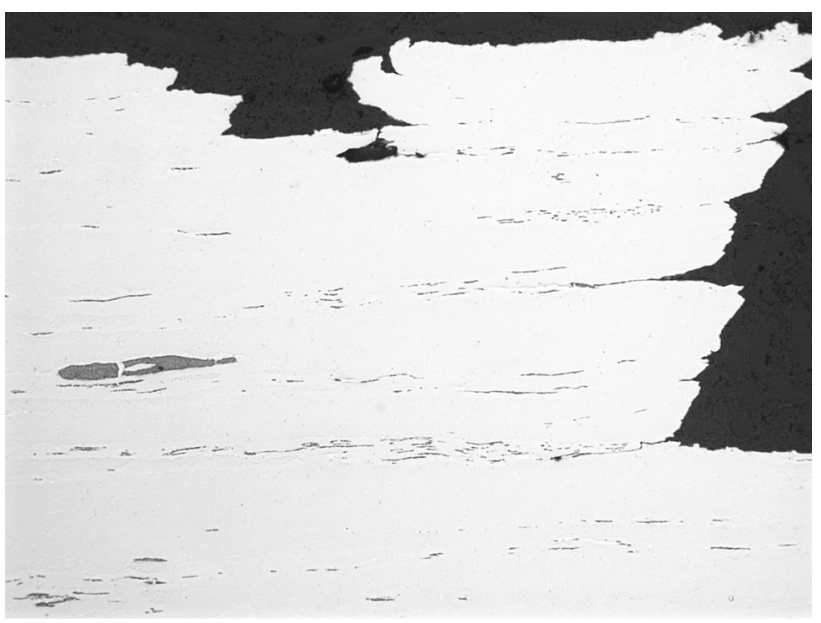

Fig. 6 Manganese sulfide stringers (gray) on a longitudinal section, showing interaction with a fracture plane and resulting in a woody fracture surface

Table 1 Standard tensile test results on AISI 1144 material

\begin{tabular}{lccc}
\hline Sample & $\begin{array}{c}\text { Ultimate tensile } \\
\text { strength }(\mathrm{MPa})\end{array}$ & $\begin{array}{c}\text { Yield strength } \\
(\mathrm{MPa})\end{array}$ & $\begin{array}{c}\text { Elongation in } \\
25 \mathrm{~mm}(\%)\end{array}$ \\
\hline Longitudinal \#1 & 1007 & 958 & 6.5 \\
Longitudinal \#2 & 1000 & 945 & 6.5 \\
Transverse \#1 & 765 & 717 & 1.5 \\
Transverse \#2 & 765 & 717 & 1.5 \\
\hline
\end{tabular}

included in this review. The following sections discuss the effects of inclusions on specific properties.

\section{Tensile Properties}

Manganese sulfides have little or no effect on yield strength, ultimate tensile strength, work hardening exponent, and work hardening rate in the longitudinal direction, which makes it advantageous for simple loading applications [8, 9]. Sulfide content is known to decrease transverse ductility (especially when reported as reduction in area), but it only slightly affects longitudinal ductility [2-4, 8-12]. This is due to the anisotropy of the MnS stringers. Improved transverse ductility can therefore be attained by desulfurization, cross rolling, and sulfide shape control [2,3]. Some investigations have found that the overall cleanliness of the alloy did not correlate well with transverse ductility, but average inclusion length did [3].

That being said, direct comparison data for the longitudinal and transverse tensile properties from a single lot of material were not available in the literature. Indeed, resulfurized grades are specified using only longitudinal properties, such as in ASTM A 311; transverse properties are 


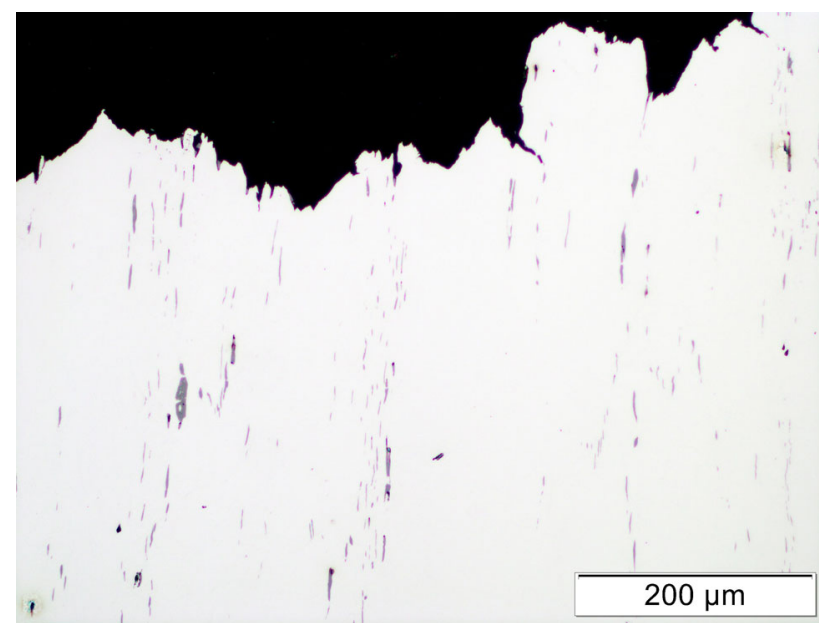

Fig. $7 \mathrm{MnS}$ inclusions at the fracture surface of a longitudinal tensile specimen. Loading is vertical in the image

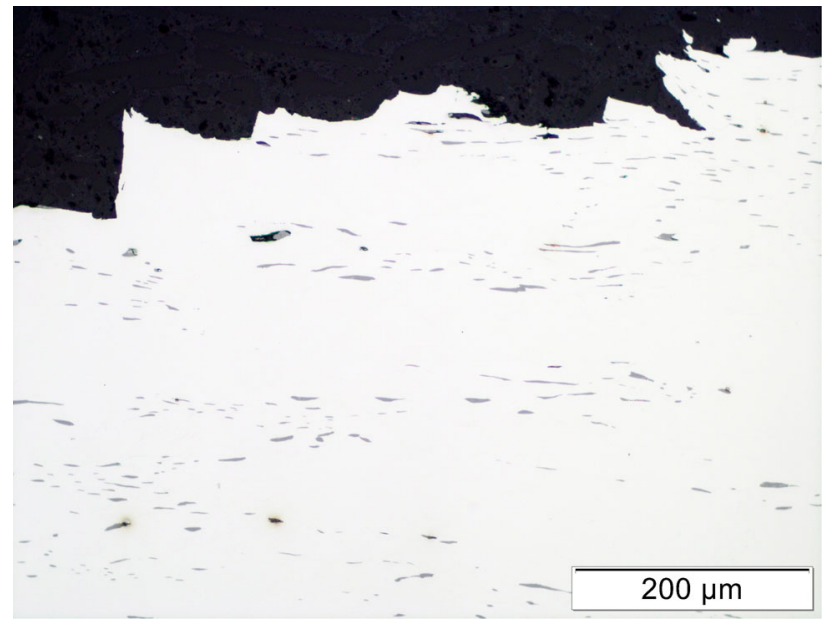

Fig. $8 \mathrm{MnS}$ inclusions at the fracture surface of a transverse tensile specimen. Loading is vertical in the image not discussed. Therefore, subsized tensile specimens were machined from a commercially available 3-inch-diameter bar of AISI 1144 material. The same sized specimens were used for both directions for the purpose of direct comparison. The results of a standard tensile test per ASTM A 370 are shown in Table 1 . The average UTS dropped by $23.8 \%$ when changing from the longitudinal to the transverse direction. Similarly, the average yield strength dropped by $24.6 \%$. The elongation dropped by $77 \%$ of the longitudinal value. Although this is a small dataset, it is clear that actual transverse property values need to be known when components will be loaded in the transverse direction. Moreover, the extremely low elongation value in the transverse direction indicates that the material behaves in a brittle manner. Therefore, it has much less crack-blunting capability and will be more susceptible to geometric stress concentrations in static loading. A typical overload fracture surface transverse to the rolling direction of an actual component was shown in Fig. 1. The inclusions associated with the tensile specimen fracture surfaces are shown in section in Figs. 7 and 8.

\section{Fatigue Resistance}

Nonmetallic inclusions are known to have a deleterious effect on fatigue resistance, in general [6, 10, 13], and they can have a greater effect than composition, microstructure, or stress gradients $[6,10]$. However, it has been stated that nonmetallic inclusions are rarely the prime cause of fatigue failures of production components because the design of the fatigue properties for the parts incorporates the effects of inclusions in the chosen material grade [6]. Although this can be said in general, the failure analyst will still encounter such failures when proper design considerations are not made.
Fig. 9 Fatigue resistance curves for AISI $4340 \mathrm{H}$ steel reproduced from Ref. [8]. The upper curve contained small inclusions, while the lower curve contained abnormally large inclusions

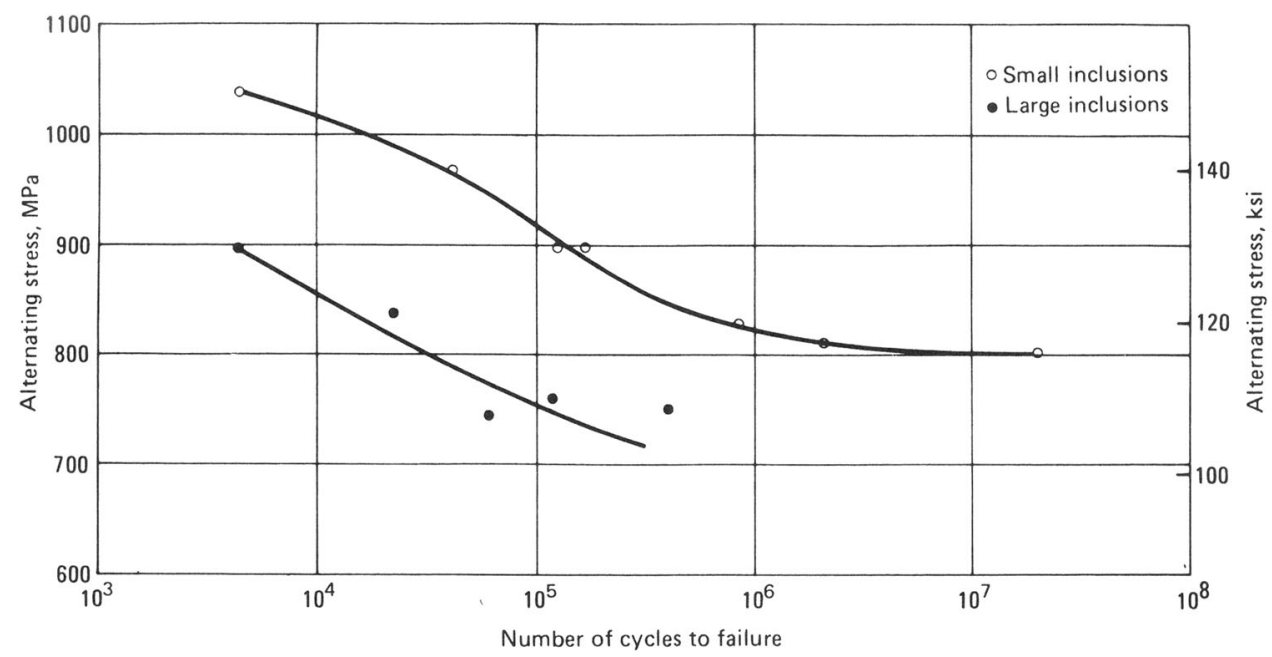


The general deleterious effect of inclusions on fatigue resistance is shown in Fig. 9 for AISI 4340H low alloy steel [14]. The type of inclusions were described as spherical and were, therefore, most likely brittle oxides. The nature of the fatigue loading, specimen orientation, and crack orientation were not provided.

Nonmetallic inclusions act as stress raisers because tensile strength is incompletely maintained within the inclusion, similar to voids [13]. As matrix strength increases, the notch effect of inclusions becomes more significant [15]. Inclusions affect mechanical properties by chemical composition, density, size, shape, orientation, interface nature, and distribution [11]. The general trends identified are as follows:

- Inclusions that are brittle compared with the steel and retain their shape during working processes (i.e., oxides, carbides, slags, refractories) have been found to be more detrimental to fatigue properties than those which deform (i.e., MnS) [13, 15].

- The main influence of inclusions is on the initiation stage of fatigue [13]. It is well known that a significant portion of the high cycle fatigue life is spent in initiation [16, 17]. In AISI 4340 steel, fatigue cracks were initiated by inclusions whenever the long axis of the inclusion was normal to a direction of principal tensile stress [15].

- There is some debate, however, since some have determined that MnS inclusions are "ineffectual stress raisers" for initiation of fatigue cracks in AISI 4340 compared with oxides [18]. This statement seems to be without weight considering the body of data produced subsequent to this paper.

- Large inclusions are more effective as initiation sites than small ones [8].

- Fatigue cracks initiate at inclusions in highly stressed regions, generally at or near external surfaces [8]. Cracks initiate at debonded or cracked inclusions, or in slip bands emanating from inclusions [8].

- Inclusion type, shape, and orientation can be more important factors than total content [4, 15]. For instance, in one study of $0.03-0.3$ wt.\% sulfur freecutting steels of $138 \mathrm{ksi}$ ultimate tensile strength (UTS), no correlation was found between sulfur content and fatigue strength [4].

Other points relating to fatigue crack initiation and propagation are

- The stress to fracture MnS inclusions loaded in the longitudinal direction is greater than the stress in the short transverse direction to part the interface [8].

- Crack formation at the tip of acicular sulfides has been observed [15].
Table 2 Fatigue endurance limit data, Ref. [11]

\begin{tabular}{lc}
\hline Wt.\% sulfur & $\begin{array}{c}\text { Ratio of longitudinal to } \\
\text { transverse endurance limit }\end{array}$ \\
\hline 0.011 & 1.09 \\
0.021 & 1.51 \\
\hline
\end{tabular}

Table 3 Crack orientation summary

\begin{tabular}{lll}
\hline Designation & \multicolumn{1}{c}{ Crack plane } & Propagation direction \\
\hline LT & Normal to longitudinal & Long transverse \\
SL & Normal to short transverse & Longitudinal \\
TS & Normal to long transverse & Short transverse \\
LS & Normal to longitudinal & Short transverse \\
ST & Normal to short transverse & Long transverse \\
\hline
\end{tabular}

- Crack propagation has been observed to take place preferentially through acicular sulfide inclusions [15].

- When loaded longitudinally, sulfides break at advanced levels of strain, while they crack from the onset of deformation when loaded in the transverse direction [4].

Early work on the effects of sulfides in bearing steels found that they are neutral or even advantageous in rolling contact fatigue situations $[11,13]$. MnS inclusions were originally found favorable for bearing steel rolling contact fatigue because of

- the absence of thermal stress after heat treatment because of the coefficient of thermal expansion for $\mathrm{MnS}$ relative to steel,

- high hot-working plasticity prevents the formation of cavities around the inclusions,

- the coating of more harmful hard inclusions by $\mathrm{MnS}$ mitigates the effects of those inclusions, and

- the absence of cracks at the sulfide-matrix boundaries after hot working which would normally initiate internal fatigue cracks [11].

However, the body of work produced later revealed this was not the case for wrought carbon and alloy steels used in bending and tension fatigue situations.

The fatigue endurance limit has been found to be anisotropic in steels with moderate sulfur content because of elongated $\mathrm{MnS}$ inclusions (Table 2) [8, 11]. In AISI 8620 case-hardened material, the following was found:

In a study of ASTM A 514 alloy steel and HY-130 steel in the martensitic conditions and 0.010 to $0.025 \mathrm{wt} . \%$ sulfur, fatigue crack propagation rates in Region II (steady state growth) were found to be accelerated or retarded as a function of sulfide content and test orientation. The LT 
Table 4 Fatigue endurance limit data, Ref. [19]

\begin{tabular}{lc}
\hline Wt.\% sulfur & Endurance limit $(\mathrm{ksi})$ \\
\hline 0.006 & 183 \\
0.015 & 174 \\
0.029 & 155 \\
\hline
\end{tabular}

Table 5 Pearlitic rail steel fatigue endurance limits, Ref. [20]

\begin{tabular}{lc}
\hline Wt.\% sulfur & Endurance limit (ksi) \\
\hline 0.020 & 50.8 \\
0.023 & 49.8 \\
0.025 & 46.3 \\
0.026 & 48.6 \\
0.030 & 46.4 \\
0.033 & 51.5 \\
\hline
\end{tabular}

orientation (see Table 3) was considered as the baseline propagation rate, wherein the cracks cut across the inclusions and traveled along slightly pancaked inclusion surfaces. The SL orientation (see Table 3) had the fastest propagation rate, where the cracks propagated along the long axis of the inclusions. Decohesion between the inclusions and the matrix was observed. Meanwhile, the TS and LS orientations (see Table 3) had slower propagation rates, where the cracks propagated across $\mathrm{MnS}$ inclusions and were deflected [5, 8 (for ASTM A533B steel)]. Total projected inclusion area on a plane parallel to the fracture plane has been shown to correlate best with fatigue crack propagation performance [5].

In a study of bending fatigue of AISI 8219 carburized steel with cracks propagating across flattened inclusions (similar to ST orientation), the endurance limit was found to be affected by sulfur content, as in Table 4 [19].

The importance of considering orientation effects on fatigue endurance limit are highlighted by comparing the baseline endurance limits found in Figs. 3-2 and 3-5 in Ref. [14] for AISI 1035 and 1141 steels, respectively [14]. The endurance limit for quenched and tempered AISI 1141 is actually higher ( $\sim 40 \mathrm{ksi})$ than that of AISI $1035(\sim 32 \mathrm{ksi})$ consistent with the expected trend for steels and the higher hardness obtainable with the higher carbon content; there was no measurable effect of the MnS inclusions in the 1144 resulfurized alloy. This seems counter to the general deleterious effects reported for inclusions in the literature until one considers the nature of the test. The data are for torsional fatigue samples, and the samples for the resulfurized grade were most likely manufactured with the long axis of the inclusions parallel to the specimen length. Therefore, the fatigue cracks, which are initiated on the plane of maximum tensile stress at the exterior surface, will propagate into the

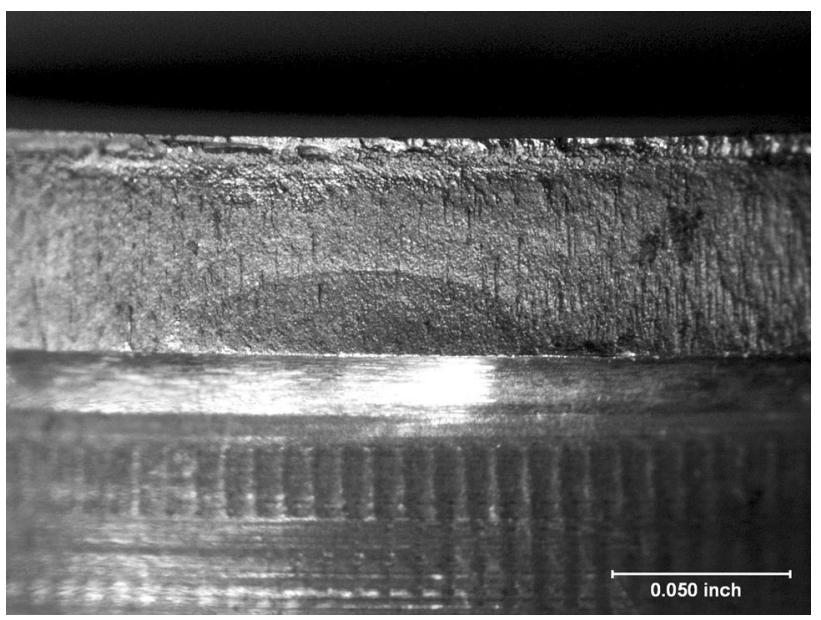

Fig. 10 Fatigue thumbnail zone on a longitudinal plane. Vertical marks on the fracture surface are MnS inclusions

sample approximately radially. This orientation results in cracks cutting across the inclusions, which slows fatigue crack propagation rate, as mentioned above.

Several reports were available for steels with pearlitic/ferritic microstructures. For pearlitic rail steels tested in the longitudinal direction, the endurance limits were found to vary with the sulfur content as mentioned in Table 5 [20]. No definite trend could be assigned to sulfur content; however, the fatigue limits presented in Table 5 were found to correspond best with the overall oxide content. Again, in these rotating bending fatigue tests, the crack propagation was perpendicular to the long axis of the inclusions.

In another study of ferritic/pearlitic steels containing elongated sulfides, a $40 \%$ increase in fatigue life was determined for samples prepared longitudinally versus transversely. Sulfide shape control was shown to give approximately isotropic fatigue life [21].

Fatigue fractures on the longitudinal plane in resulfurized steels exhibit the same features as other steels, superimposed with $\mathrm{MnS}$ inclusions (or their mating matrix surfaces) where the fracture has propagated along the interface of the inclusion and matrix. Figure 10 shows a classic thumbnail-shaped fatigue origin region on a longitudinal plane. Careful inspection reveals vertical marks that are evidence of the crack propagating along MnS inclusions. Sulfide inclusions near a fatigue origin on a longitudinal plane are shown in Fig. 11. The matrix fracture around the inclusions exhibits the same patterns as other steels, such as a feathery or "mottled" appearance of fatigue through martensite (Fig. 12) or fatigue striations (Fig. 13).

\section{Fracture Toughness}

Plain strain fracture toughness is a measure of a material's resistance to unstable crack growth in the presence of a 


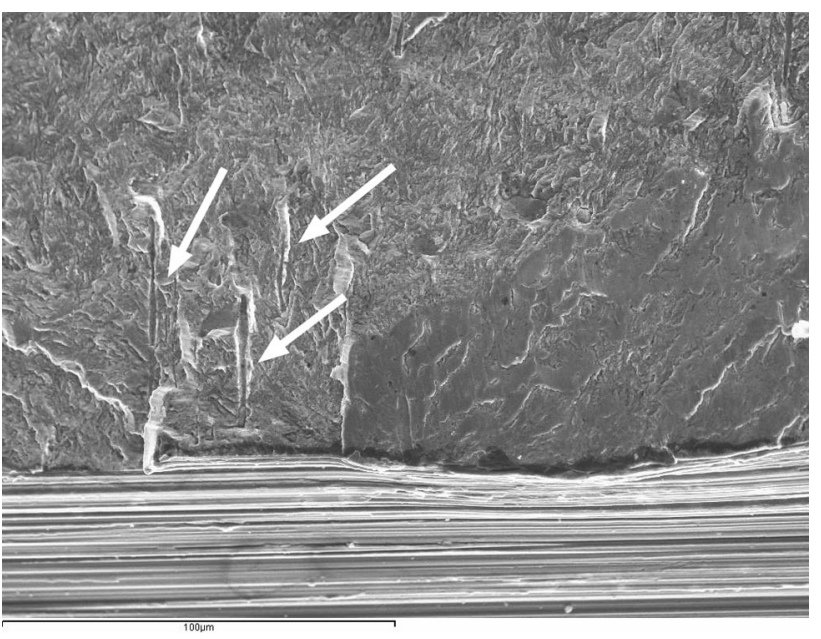

Fig. 11 Manganese sulfide inclusions (arrows) near a fatigue origin

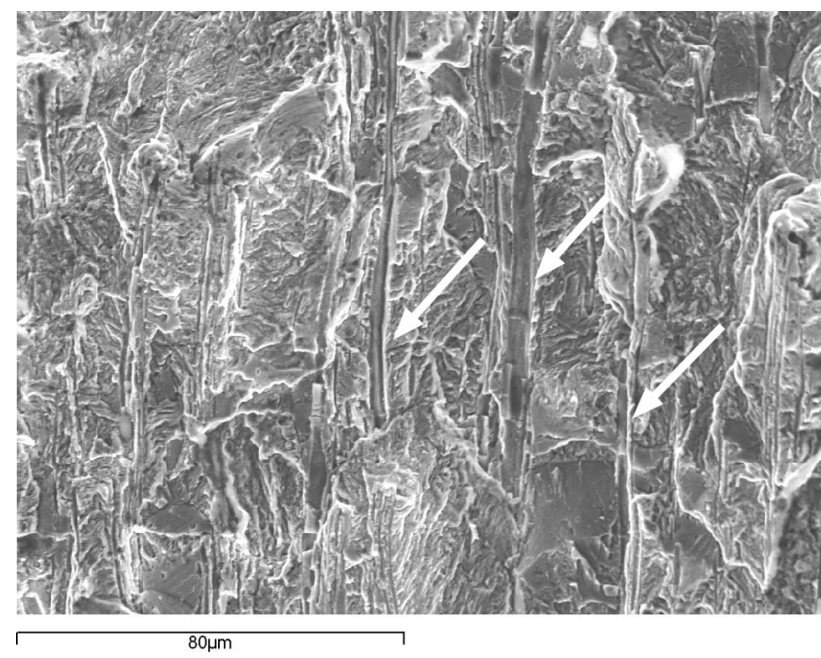

Fig. 12 A fatigue fracture showing $\mathrm{MnS}$ inclusions (arrows) and mottled matrix morphology

preexisting flaw. The parameter measured is termed $\mathrm{K}_{\mathrm{IC}}$. Fracture toughness has long been found lowest in the ST and SL orientations, wherein the crack propagates parallel to the elongated dimensions of sulfide inclusions [8]. Data from several case studies are presented as follows.

Studies on AISI 4340, 4130, and 300M steels have found that undissolved carbides and sulfide inclusions can act as crack nuclei and lower fracture toughness $25-50 \%$ [22]. In a study of AISI 4340 steel, the fracture toughness trended from 56.8 to $40.5 \mathrm{ksi}-\sqrt{ }$ inch with the increasing inclusion content [15]. Test direction was not provided. Another study of AISI 4340 with $220 \mathrm{ksi}$ UTS found that the transverse fracture toughness dropped from 97.2 to $67.9 \mathrm{ksi}-\sqrt{ }$ inch with a sulfur content variation from 0.004 to $0.013 \mathrm{wt} . \%$ [11].

A study of structural steels with $285 \mathrm{ksi}$ UTS found that the longitudinal fracture toughness dropped from 74.6 to

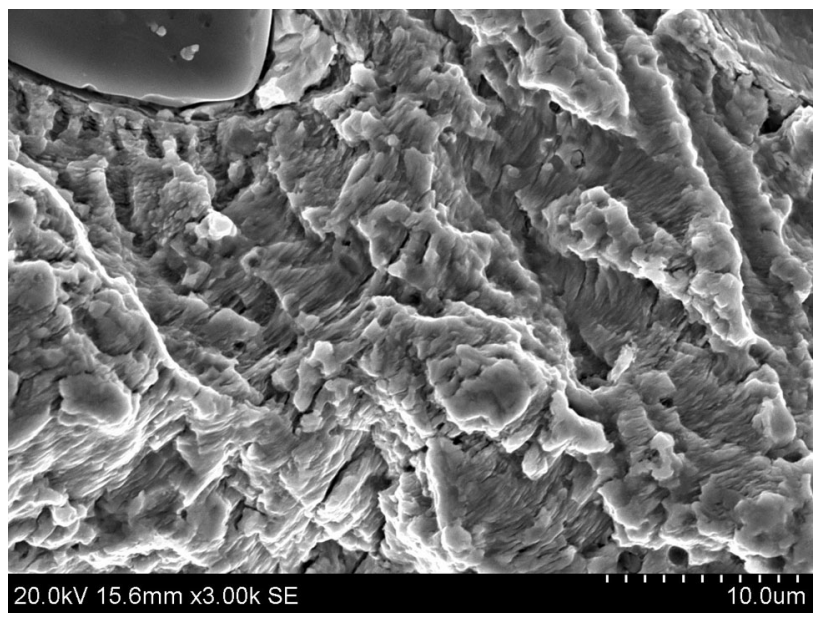

Fig. 13 Fatigue striations (parallel lines) observed on a fracture near a $\mathrm{MnS}$ inclusion (top left)

$38.3 \mathrm{ksi}-\sqrt{ }$ inch with a sulfur content variation from 0.005 to 0.025 wt. $\%$ [11].

In a study on SAE 4335 with intentional impurity additions, fracture toughness was found to be greatly affected by sulfur content. The greatest effect of other impurities was in combination of two or more with sulfur, as shown in Table 6 [23]. The test direction for this data was not provided. The $400^{\circ} \mathrm{C}$ temper condition is in the range of temper embrittlement, as highlighted by the sample containing arsenic.

A study on AISI 4340 steel that investigated the anisotropy of fracture toughness due to $\mathrm{MnS}$ aspect ratio (by controlled rolling) indicated improvements with shorter aspect ratio at constant sulfur content $(0.013 \mathrm{wt} . \%)$. The improvement when testing in the longitudinal direction is also evident in Table 7 [24].

Conditional fracture toughness data were available as a function of sulfur content in pearlitic rail steel, which are included here for completeness [20]. The test direction was not provided. The values are conditional because all of the requirements for a valid $\mathrm{K}_{\mathrm{IC}}$ of ASTM E 399 were not met by the test samples. However, the trend can still be evaluated. The conditional fracture toughness data are shown in Table 8 , and a reduction in conditional fracture toughness was observed with the increasing sulfur content.

\section{Notch Toughness}

Notch toughness characterizes a material's ability to absorb energy during high strain rate loading (i.e., impact). The Charpy V-Notch (CVN) impact test has become the standard for this property. A plot of CVN absorbed energy versus test temperature for carbon or alloy steel will generally have a sigmoidal shape exhibiting a lower shelf 
Table 6 Fracture toughness data, Ref. [23]

\begin{tabular}{lll}
\hline $\begin{array}{l}\text { Added element } \\
\text { content (wt.\%) }\end{array}$ & $\begin{array}{c}\text { Tempering } \\
\text { temperature }\left({ }^{\circ} \mathrm{C}\right)\end{array}$ & $\begin{array}{l}\mathrm{K}_{\mathrm{IC}}(\mathrm{ksi}-\sqrt{\text { inch }}) \\
(\text { multiple samples })\end{array}$ \\
\hline 0 & 100 & 91,83 \\
& 200 & 129,126 \\
$0.015 \mathrm{~S}$ & 400 & 140 \\
& 100 & $72,65,63$ \\
$0.014 \mathrm{~S}, 0.017 \mathrm{P}$ & 200 & $80,68,64$ \\
& 100 & $62,61,59$ \\
$0.012 \mathrm{~S}, 0.11 \mathrm{Cu}$ & 200 & $71,70,59$ \\
& 400 & 71,71 \\
$0.012 \mathrm{~S}, 0.11 \mathrm{Sn}$ & 100 & $67,57,62$ \\
& 200 & 94,89 \\
& 400 & 131,114 \\
$0.014 \mathrm{~S}, 0.10 \mathrm{As}$ & 100 & $60,55,50$ \\
& 200 & 71,70 \\
& 400 & 98,87 \\
& 100 & $63,63,54$ \\
& 200 & $69,67,66$ \\
& 400 & 39,36 \\
& & \\
& &
\end{tabular}

Table 7 Fracture toughness data, Ref. [24]

\begin{tabular}{lcc}
\hline $\begin{array}{l}\text { Sulfide inclusion } \\
\text { aspect ratio }\end{array}$ & $\begin{array}{c}\text { Avg. longitudinal } \\
\mathrm{K}_{\mathrm{Ic}}(\mathrm{ksi}-\sqrt{ } \text { inch })\end{array}$ & $\begin{array}{c}\text { Avg. transverse } \\
\mathrm{K}_{\mathrm{Ic}}(\mathrm{ksi}-\sqrt{\text { inch }})\end{array}$ \\
\hline 17.5 & 40.3 & 34.9 \\
10.2 & 45.7 & 42.3 \\
6.2 & 50.5 & 46.5 \\
3.8 & 58.9 & 49.8 \\
\hline
\end{tabular}

Table 8 Conditional fracture toughness data, Ref. [20]

\begin{tabular}{lc}
\hline Wt.\% sulfur & $\mathrm{K}_{\mathrm{Q}}(\mathrm{ksi}-\sqrt{\text { inch }})$ \\
\hline 0.020 & 45.4 \\
0.023 & 42.5 \\
0.025 & 39.9 \\
0.026 & 39.9 \\
0.030 & 39.0 \\
0.033 & 38.5 \\
\hline
\end{tabular}

energy at low temperatures and an upper shelf energy at high temperatures. The curve is also characterized by the ductile-to-brittle transition temperature (DBTT) or fracture appearance transition temperature (FATT) between these two extremes.

Manganese sulfide inclusions are known to affect the upper shelf energy but not the transition temperature in both the longitudinal and transverse directions $[2,8,9,11,25]$. A high correlation has been found between the upper shelf energy and a single parameter, $\mathrm{P}$, which is the total projected

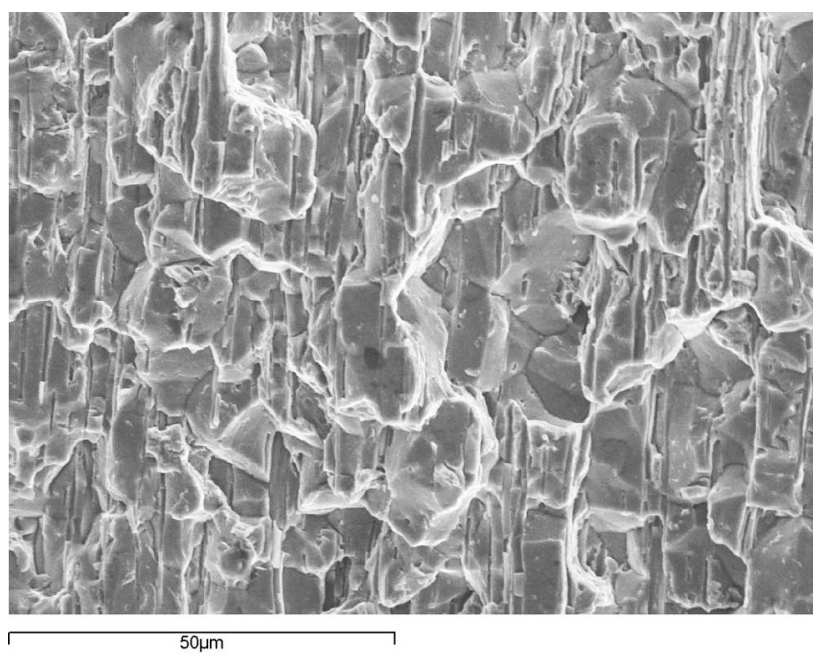

Fig. 14 SEM image of manganese sulfide inclusions (vertical features) on a longitudinal fracture plane of embrittled material, hence the intergranular fracture of the matrix

Table 9 Charpy impact strength data, Ref. [11]

\begin{tabular}{lc}
\hline Wt.\% sulfur & $\begin{array}{c}\text { Ratio of longitudinal to } \\
\text { transverse impact strength }\end{array}$ \\
\hline 0.011 & 3.0 \\
0.030 & 5.4 \\
0.031 & 6.3 \\
0.065 & 7.6 \\
0.074 & 7.9 \\
0.069 (globular) & 2.75 \\
0.071 (globular) & 3.75 \\
\hline
\end{tabular}

inclusion length per unit area on a plane parallel to the fracture plane $[8,9,12]$. Upper shelf energy decreases monotonically with increasing P. This parameter accounts for the anisotropy in properties between the longitudinal and transverse directions. Transverse notch toughness can be improved by shape control, desulfurization, or cross rolling $[2,3]$. Many studies report a monotonic drop in upper shelf energy with the increasing sulfur content, rather than total projected length, $\mathrm{P}$, since there is a general correlation when not shape controlled [25]. The fracture appearance of impact-fractured resulfurized steels can show superimposed $\mathrm{MnS}$ inclusions (or mating matrix interface) with brittle fracture in the matrix. Figure 14 shows an example of inclusions on a fracture plane exhibiting an overall brittle intergranular appearance since the matrix was temper embrittled. For this sample, the embrittlement of the matrix was more significant than the presence of elongated inclusions on the fracture plane. However, inclusions have been shown to be the dominant factor in other situations.

However, one study on $0.30 \mathrm{wt} \%$ carbon, nickelchromium-molybdenum straight-rolled steel indicated a 
constant anisotropy ratio of 3.5 between longitudinal and short transverse impact energies, regardless of sulfur content between 0.005 and 0.179 wt.\% [25].

The effects of elongated sulfides as a function of total content and shape were shown in AISI 4137 steel with 260 ksi UTS (Table 9). There was only a moderate effect of sulfur on longitudinal impact strength [11]. The large effect of inclusion shape can be seen for the globular $\mathrm{MnS}$ in Table 9, reflecting the changes in projected length, $\mathrm{P}$.

\section{Conclusion}

This literature review assessed the effects of inclusions in carbon and alloy steels on their mechanical properties and potential to cause failure. Inclusions, including brittle oxides and more ductile manganese sulfides (MnS), affect fatigue endurance limit, fatigue crack propagation rate, fracture toughness, notch toughness, transverse tensile properties, and anisotropy of these properties with respect to the rolling direction. MnS particularly affects anisotropy due to its elongated morphology after hot rolling. Therefore, significant potential for failure exists if isotropic properties are assumed. Metallurgical and fractographic techniques have readily identified which direction cracks propagate relative to the rolling direction.

Specific data indicated that in certain alloys and testing situations, fatigue endurance limit dropped $28 \mathrm{ksi}$ with an increase in sulfur to only 0.029 wt.\%. Sulfides have little or no effect on yield strength, ultimate tensile strength, work hardening exponent, and work hardening rate in the longitudinal direction relative to non-resulfurized grades; however, transverse properties measured by the author were approximately $25 \%$ less than the longitudinal properties, with transverse ductility more significantly affected. Fracture toughness can be lowered $25-50 \%$ with increased sulfur concentrations. Sulfur content had little effect on notch toughness in the longitudinal direction, but transverse notch ductility decreased significantly as indicated by a change in anisotropy ratio by $260 \%$.

These data serve to warn designers to systematically consider loading conditions and loading directions when specifying resulfurized grades of steel. It is clear that without due consideration of these details, unexpected failures of components can be observed in tensile, impact, or fatigue modes. This is especially true if designers are unaware of the anisotropic properties for the material, or if resulfurized grades are specified later in the manufacturing process due to economic factors. Proper design would utilize the correct property values for the transverse direction of the material. Since these values are generally not specified or available in literature, testing may be necessary once the material and material supplier are chosen. Additionally, the directionality of the stock material relative to the part geometry may need to be specified on the drawings.

Post-design economic decisions on changing to a resulfurized grade for more efficient machining must be discussed with design engineers and a re-evaluation must be performed. In addition, the economic gains for small production lots may be insignificant compared to the potential for failures and warranty claims.

\section{References}

1. W.F. Smith, Structure and Properties of Engineering Alloys, 2nd edn. (McGraw-Hill, New York, 1993), p. 95

2. I. Kozasu, J. Tanaka, Effects of sulfide inclusions on notch toughness and ductility of structural steels, in Sulfide Inclusions in Steel: Proceedings of an International Symposium, American Society for Metals, 1975

3. A.J. DeArdo, E.G. Hamburg, Influence of elongated inclusions on the mechanical properties of high strength steel plate, in Sulfide Inclusions in Steel: Proceedings of an International Symposium, American Society for Metals, 1975

4. J. Bellot, M. Gantois, The influence of 'sulfide-type' inclusions on the mechanical properties of construction steels. Trans. Iron Steel Inst. Jpn. 18(9), 546-553 (1978)

5. A.D. Wilson, Fatigue crack propagation in steels: the role of inclusions, Fracture: Interactions of Microstructure, Mechanisms and Mechanics (The Metallurgical Society of AIME, Warrendale, 1984), pp. 235-254

6. ASM Metals Handbook, vol. 1 (ASM International, 1990), pp. 149-156

7. S.R. Lampman (ed.), ASM Handbook, in Properties and Selection: Irons, Steels, and High-Performance Alloys, vol 1 (ASM International, Materials Park), p. 597

8. W.C. Leslie, Inclusions and mechanical properties. ISS Trans. 2, 1-24 (1983)

9. D.K. Biswas, M. Venkatraman, C.S. Narendranath, U.K. Chatterjee, Influence of Sulfide inclusion on ductility and fracture behavior of resulfurized HY-80 steel. Metall. Trans. A 23(5), 1479-1492 (1992)

10. ASM Metals Handbook, Desk Edition, 2nd edn. (ASM International, 1998), pp. 224, 228

11. L.G. Seraphin, R.H. Tricot, Effect of sulfide inclusions on mechanical properties of ultra-high-strength steels, in Sulfide Inclusions in Steel: Proceedings of an International Symposium, American Society for Metals, 1975

12. W.A. Spitzig, Effect of sulfides and sulfide morphology on anisotropy of tensile ductility and toughness of hot-rolled C-Mn steels. Metall. Trans. A 14(3), 471-484 (1983)

13. R. Kiessling. Non-Metallic Inclusions in Steel, Part III, Iron and Steel Institute [London], 1968

14. H.E. Boyer (ed.) Atlas of Fatigue Curves, American Society for Metals, 1986

15. P.A. Thornton, The influence of nonmetallic inclusions on the mechanical properties of Steel: a review. J. Mater. Sci. 6, 347-356 (1971)

16. T. Gross, Micromechanisms of monotonic and cyclic crack growth, ASM Handbook, in Fatigue and Fracture, vol 19 (ASM International, Materials Park, 1996), p. 49

17. P. Lukas, Fatigue crack nucleation and microstructure, ASM Handbook, vol. 19, Fatigue and Fracture (ASM International, Materials Park, 1996), p. 96

18. J. Lankford, F.N. Kusenberger, Initiation of fatigue cracks in 4340 steel. Metall. Trans. 4, 553-559 (1973) 
19. K.A. Erven, D.K. Matlock, G. Krauss, Effect of sulfur on bending fatigue of carburized steel. J. Heat Treat. 9(1), 27-35 (1991)

20. S.K. Dhua, A. Ray, S.K. Sen, M.S. Prasad, K.B. Mishra, S. Jha, Influence of nonmetallic inclusion characteristics on the mechanical properties of rail steel. J. Mater. Eng. Perform. 9(6), 700-709 (2000)

21. R. Pearce, A.A. Mazhar, Fatigue behaviour of certain highstrength, low-alloy steel sheets. Met. Technol. 3, 79-85 (1976)

22. E.R. Parker, V.F. Zackay, Microstructural features affecting fracture toughness of high strength steels. Eng. Fract. Mech. 7(3), 371-375 (1975)
23. C.L.M. Cottrell, Effect of impurities on fracture toughness of high-strength steel, Fracture Toughness of High-Strength Materials: Theory and Practice, vol. 120 (ISI Publication, London, 1970), pp. 112-115

24. Y. Tomita, Effect of hot-rolling reduction on shape of sulfide inclusions and fracture toughness of AISI 4340 ultrahigh strength steel. Metall. Trans. A 19(6), 1555-1561 (1988)

25. J.M. Hodge, R.H. Frazier, F.W. Boulger, The effects of sulfur on the notch toughness of heat-treated steels. Trans. Metall. Soc. AIME 215(10), 745-753 (1959) 